INTERNATIONAL JOURNAL OF RESEARCHES IN BIOSCIENCES, AGRICULTURE AND TECHNOLOGY

(C) VISHWASHANTI MULTIPURPOSE SOCIETY (Global Peace Multipurpose Society) R. No. MH-659/13(N) www.vmsindia.org

\title{
A STUDY ON ANTIMICROBIAL SUSCEPTIBILITY PATTERNS OF STAPHYLOCOCCUS AUREUS FROM TERTIARY CARE CENTERS CHANDRAPUR (M.S.) INDIA
}

\author{
Y. W. There ${ }^{1}$, V. S. Wadhai ${ }^{1}$ and P. R. Bhandari ${ }^{2}$ \\ ${ }^{1}$ CHLRM, Sardar Patel Mahavidyalaya, Chandrapur(M.S), India442402 \\ ${ }^{2}$ Sewadal mahila mahavidyalaya, nagpur \\ yogeshwthere@gmail.com
}

\begin{abstract}
:
Antibiotic resistant pathogens constitute an important and growing threat to the public health. Antibiotic resistance occurs when a microbe acquires a gene, which allows the microbe to inactivate the antibiotic or otherwise nullify its antimicrobial activity. Staphylococci are widespread pathogens and are frequently associated with hospital-acquired infections. Healthcare-associated methicillin-resistant S. aureus (MRSA) is a major cause of nosocomial infections worldwide, with significant attributable morbidity and mortality in addition to pronounced healthcare costs. Many hospitals struggle with increasing amounts of MRSA, which are "multi-resistant" against all beta-lactam antibiotics. Often, applicable antibiotics for treatment are only glycopeptides like vancomycin. The main objectives of this study was to find out the antimicrobial susceptibility pattern of S.aureus isolates, the prevalence of methicillin resistant S.aureus and demonstration of Vancomycin resistance among MRSA strains Method: A total 139 clinical samples like pus, sputum and burn wounds are screened for the isolation of S.aureus strains. The pure isolates of coagulase positive S.aureus were tested for antimicrobial susceptibility by using standard methods. Results: Out of 139 clinical specimens 100 samples were found to be coagulase negative S.aureus. High resistance was observed against, penicillin, erythromycin and tetracycline. High sensitivity was recorded against amikasin, chloramphenicol \& Gentamycin. Of the isolates 76 isolates were methicillin resistant S.aureus (MRSA). Vancomycin resistant among MRSA isolates was found 14\%. Conclusion: Our study emphasizes the need for continuous monitoring of the antimicrobial susceptibility pattern of S.aureus isolates including MRSA for the selection of appropriate therapy. In Chandrapur, from the present findings it appears that the spread of MRSA in community is very high and the vancomycin which is the last choice for the treatment MRSA strains also shown resistant. So there is need of high alert in hospital settings and need of continuous monitoring and surveillance to control resistance.
\end{abstract}

Keywords: MRSA, VRSA, Antibiotics and Oxacillin.

\section{Introduction}

Antibiotic resistant pathogens constitute an important and growing threat to the public health. Antibiotic resistance occurs when a microbe acquires a gene, which allows the microbe to inactivate the antibiotic or otherwise nullify its antimicrobial activity. This may occur as a spontaneous, genetic mutation or involve acquisition of a genetic element such as plasmid, transposon and gene cassette. Staphylococci are widespread pathogens and are frequently associated with hospital-acquired infections. Healthcare-associated methicillinresistant $\mathrm{S}$. aureus (MRSA) is a major cause of nosocomial infections worldwide, with significant attributable morbidity and mortality in addition to pronounced healthcare costs. Many hospitals struggle with increasing amounts of MRSA, which are "multi-resistant" against all beta-lactam antibiotics. Often, applicable antibiotics for treatment are only glycopeptides like vancomycin and teicoplanin9. The Staphylococci were initially identified as grape like cluster of bacteria isolat

\section{Material and Methods:}

The present study was conducted on the clinical specimens collected from civil hospital
Chandrapur district. Total 139 clinical specimens was collected, out of which 100 specimen was found to be coagulase negative Staphylococcus aureus. Of the 100 clinical isolates, 78 isolates of S.aureus were from pus , 13 were from burn patient and 9 from sputum sample. Standard procedure was followed for isolation and identification of S.aureus and to perform antimicrobial activit7. In brief the specimen was collected in sterile container and transport to the laboratory. The specimen then immediately inoculated nutrient broth tube and incubate overnight at $370 \mathrm{C}$ for enrichment. Then the loop full of sample transfer to the Mannitol Salt Agar and were incubated at 370C for 18-24 hours. The suspected isolated colonies were exposed to Gram's staining and other biochemical test. Staphylococcus aureus organisms were confirmed mainly by positive DNase test and coagulase tests. After confirmation of S.aureus isolates were subjecte

\section{Result and Discussion:}

The present study identified 100 coagulase positive Staphylococcus aureus out of 139 clinical specimen. From 100 positive isolates $76(76 \%)$ isolates were accounted MRSA and rest of MSSA (26\%). Most of the MRSA 
samples were isolated from pus, sputum and burn patient. The percentage of MRSA in Pus, Sputum and Burn was $85.89 \%, 33.33 \%$ and $46.15 \%$ respectively; whereas the percentage of
MSSA in Pus, Sputum and Burn 14.11\%, $66.67 \%$ and $53.85 \%$ respectively. (Table 1 ) (Graph 1)

Table 5: Comparison of antimicrobial susceptibility pattern of methicillin resistant S.aureus strains identified on disc diffusion with MIC (Total=76)

\begin{tabular}{|c|c|c|c|c|c|c|c|c|c|}
\hline \multirow{4}{*}{$\begin{array}{l}\text { Sr. } \\
\text { No }\end{array}$} & \multirow{4}{*}{$\begin{array}{l}\text { Name of } \\
\text { Antibiotics }\end{array}$} & \multicolumn{8}{|c|}{ Antimicrobial Susce } \\
\hline & & \multicolumn{4}{|c|}{ Disc Diffusion } & \multicolumn{4}{|c|}{ MIC } \\
\hline & & \multicolumn{2}{|c|}{ Sensitivity } & \multicolumn{2}{|c|}{ Resistant } & \multicolumn{2}{|c|}{ Sensitivity } & \multicolumn{2}{|c|}{ Resistant } \\
\hline & & No. & $\%$ & No. & $\%$ & & $\%$ & No. & $\%$ \\
\hline 1 & & 0 & 0 & 76 & 10 & 08 & 10.52 & 68 & 89.47 \\
\hline 2 & Vancomycin & 65 & 85.52 & 11 & 14.47 & 69 & 90.78 & 07 & 9.21 \\
\hline
\end{tabular}

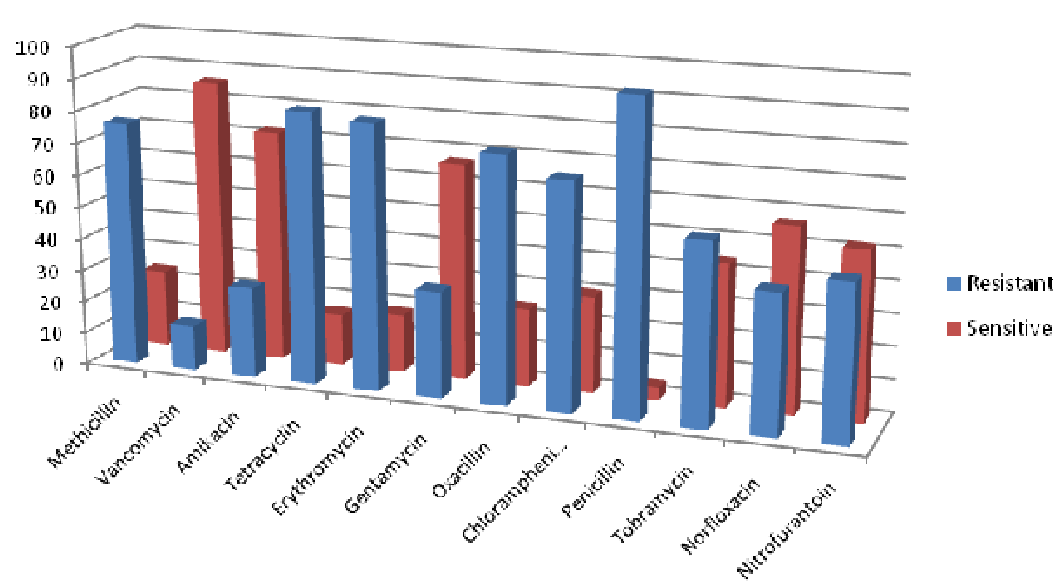

Graph-4 : Result of Antibiotic sensitivity Test on Disc Diffusion

\section{Discussion:}

This study was conducted at Chandrapur district Which is declared as tribal region. Very few reports are available on MRSA from this region. In this study we have found the prevalence rate of MRSA is $76 \%$ It shown that there is significant rise in antimic

\section{Conclusion:}

The present study first time exposed the vancomycin resistance in this part of India and prevalence rate of MRSA is $76 \%$. These findings are suggest the need of regularly monitoring the antibiotic resistance patterns of MRSA and implementation of strict rules and regulation on antibiotic usages. The most effective way to prevent emergence of antibiotic resistance is by continuous surveillance of antibiotic resistance profile, reduce misused of antimicrobial drug by proper diagnostic procedure, development of significant new antimicrobial agents and also need of effective education.

\section{Reference:}

[1] Assadullah, S., Kakru, D.K., Thoker, M.A., Bhat, F.A. and Hussain N, Shah, A. (2003): Emergence of low level Vancomycin resistance in MRSA. Indian J Med Microbiol, vol 21:Pp. 196-198.
[2] Baird, D. (1996): Staphylococcus: cluster forming gram positive cocci. In: Collee, J.G., Fraser, A.G., Marmion, B.P., Simmons, A., editor. Mackie and McCartney Practical Medical Microbiology. Vol 14: Pp. 245-261

[3] Bauer, A.w., Kirby, w.M.M., Sherris, J.C., and Turck, M. (1966): Antibiotics susceptibility testing by a standardized single disk method. Am J. Clin Pathol, vol 45:Pp.493.

[4] Brooks, G.F., Butel, J.S. and Morse,S.A. (2004): The Staphylococci. In : Medical Microbiology, 23rd Ed., Meclnick, J., Adelberg (eds): 223-230. Mc Graw Hill, New York, USA.

[5] Chambers HF, Hadley WK, and Jawetz E. (1998) Aminoglycosides and spectinomycin. In B. C. Katzung (ed.), Basic and clinical pharmacology. Appleton and Lange, Stamford, Pp. 752-760

[6] Chambers, H. F., W. K. Hadley, and E. Jawetz.(1998) Beta-lactam antibiotics and other inhibitors of cell wall synthesis. In B. C. Katzung (ed.), Basic and clinical pharmacology. Appleton and Lange, Stampford, Pp.724-742

[7] CLSI (2006): Performance standards for antimicrobial susceptibility testing,fifteenth International supplement, CLSI document $\mathrm{M}$ 100-S16, Vol. 26-3; M7-A7, Vol.26-2; M2-A9, Vol. 26-1. Wayne, PA. USA 
[8] Hiramatsu, K., Hanaki, ,H, Ino, T., Yabuta, K., Oguri, T., Tenover, F.C. (1997): Methicillin resistant Staphylococcus aureus clinical strain with reduced Vancomycin susceptibility. J Antimicrob Chemother, vol 40: Pp.135-136

[9] Hsu,L.Y., Wijaya,L. and Tan, B. H. (2005). Management of healthcare-associated Methicillin-resistant Staphilococcus aureus. Expert.Rev Anti Infect. Ther. Vol 3:Pp. 893-905.

[10] Isenberg, H. D. (1998): Agar screening test to detect oxacillin (Methicillin) resistant Staphilococcus Spp. In. Essential procedure for Clinical Microbiology.ASM press Washinton DC. Pp.232-234

[11] Khan, F., Shukla, I., and Rivizi, M. (2011): The role of non-beta-lactum antimicrobial and screening for Vancomycin resistance in MRSA. Malaysian J Microbiol, vol 7: Pp.66-70

[12] Naik. D and Teclu A. A (2009): study on antimicrobial susceptibility pattern in clinical isolates of Staphylococcus aureus in Eritrea. Pan African Medical Journal, vol 3:1

[13] Ogeston, A. (1881): Report upon microorganism in surgical diseases. Br. Med.J. vol 1:Pp. 369-37

[14] Saravanan M. Nanda A. and Tesfaye T. (2013) Antibiotic Susceptibility Pattern of Methicillin Resistant Staphylococcus aureus from Septicemia Suspected Children in Tertiary Hospital in Hosur, South India American Journal of Microbiological Research,, Vol. 1:Pp. 21-24 
[15] Tiwary, H. K. and Sen, M. R. (2006): Emergence of Vancomycin resistant Staphylococcus aureus (VRSA) from tertiary care hospital from Northern part of India. BMC Infectious Dis, vol 6: Pp.156.

[16] Venubabu, T., Channappa,T.S and Subhaschandra, M. G. (2011) Vancomycin resistant among MRSA from intensive care unit of tertiary care hospital in Hydrabad. Indian J Med Res 134:Pp: 704708 